Marquette University

e-Publications@Marquette

College of Education Faculty Research and

Publications

Education, College of

$1-1-2014$

Home-Based Parent-Child Therapy in LowIncome African American, Caucasian, and Latino Families: A Comparative Examination of Treatment Outcomes

Brittany L. Gresl

Marquette University

Robert A. Fox

MarquetteUniversity, robert.fox@marquette.edu

Alicia Fleischmann

Marquette University

Accepted version. Child \& Family Behavior Therapy, Vol. 36, No. 1 (2014): 33-50. DOI. (C) 2014

Taylor \& Francis (Routledge). Used with permission. 


\title{
Home-Based Parent-Child Therapy in Low-Income African American, Caucasian, and Latino Families: A Comparative Examination of Treatment Outcomes
}

\author{
Brittany L. Gresl \\ Department of Counselor Education and Counseling Psychology, \\ College of Education, Marquette University \\ Milwaukee WI \\ Robert A. Fox \\ Department of Counselor Education and Counseling Psychology, \\ College of Education, Marquette University \\ Milwaukee WI \\ Alicia Fleischmann \\ Department of Counselor Education and Counseling Psychology, \\ College of Education, Marquette University \\ Milwaukee WI
}

\footnotetext{
Abstract. This study examined parent and child treatment outcomes for a home-based Parent-Child Therapy (PCT) program for 66 children from families living in poverty. African American, Caucasian, and Latino families were examined to determine if an evidence-based program would produce 
NOT THE PUBLISHED VERSION; this is the author's final, peer-reviewed manuscript. The published version may be accessed by following the link in the citation at the bottom of the page.

similar results across different ethnic groups. The results showed that caregivers across the three ethnic groups reported improved child challenging behavior, increased positive parent-child interactions, improved parental expectations, higher levels of nurturing, and less reliance on verbal and corporal punishment as a form of discipline. Practical implications for these results are discussed.

Keywords: home-based, parent-child therapy, behavior problems, Latino, African American, Caucasian, young children, poverty

Behavior problems in young children are common and begin in the toddler and preschool years (Fox \& Holtz, 2009; Keenan \& Wakschlag, 2000). For most children, these behaviors are a typical part of child development and fade over time; however, $10-15 \%$ of young children have moderate to severe behavioral difficulties and $50 \%$ of these children will continue to exhibit problem behaviors into the elementary school years (Campbell, 1995). This number is nearly double for children and families living in poverty, many of whom are ethnic minorities (Anthony, Anthony, Morrel, \& Acosta, 2005; Coard, Wallace, Stevenson, \& Brotman, 2004). Without intervention, many of these children go on to develop more serious and intractable behavior problems into adolescence and even adulthood (Breitenstein et al., 2007; Keenan, Shaw, Delliquadri, Giovannelli, \& Walsh, 1998).

Early intervention programs that address problem behaviors in children have been shown to be effective for families that are engaged in treatment (Eyberg, Nelson, \& Boggs, 2008). For example, the use of parent training for early child behavior problems is successful in reducing childhood aggression, tantrums, and noncompliance, as well as increasing positive parenting behaviors (Webster-Stratton \& Hammond, 1997). Programs like Parent-Child Interaction Therapy (PCIT), the Incredible Years Parenting program (IYP), and the Parenting Young Children program (PYC) demonstrate that parent training is a well-recognized and accepted approach for decreasing child problem behaviors (Eyberg, Boggs, \& Algina, 1995; Fox \& Nicholson, 2003; Gross et al., 2009; Webster-Stratton, Reid, \& Hammond, 2001).

Despite the effectiveness of parent training programs, most of the research reported thus far has focused on children from intact, Caucasian, middle-class families (Coard et al., 2004). These families 
typically are provided treatment services in a group format at clinics or university settings. There is a limited body of literature regarding the effectiveness of these programs with low-income populations in the community, including ethnically diverse populations (Coard et al., 2004). This is surprising given that ethnic minority children are disproportionally represented among those exhibiting behavioral and emotional problems (Gross et al., 2009). Low-income African American and Latino children are less likely to access mental health services; for example, Latino children are 2.6 times less likely to have their mental health needs met than Caucasian children (Kataoka, Zhang, \& Wells, 2002; Substance Abuse and Mental Health Services Administration [SAMHSA], 2001). Complicating the work with these more stressed families are the reported higher rates of treatment dropout and the presence of significant psychosocial barriers to their treatment participation (Fernandez, Butler, \& Eyberg, 2011; Reid, WebsterStratton, \& Beauchaine, 2002).

A challenge in examining the effectiveness of parent training programs with low-income and ethnic minority groups is that not all families who participate necessarily benefit from parent training (Sanders, Markie-Dadds, Tully, \& Bor, 2000). While this may be due to having limited resources associated with living in poverty, it also could be a result of the treatment program failing to address the unique psychosocial needs of these families (Matos, Torres, Santiago, Jurado, \& Rodriguez, 2006). Some unique psychosocial risk factors for treatment attrition include socioeconomic disadvantage, parental stress, parent psychopathology, delayed child developmental functioning, dysfunctional child-rearing practice, lack of transportation, and other barriers to treatment (Kazdin, Mazurick, \& Bass, 1993). Researchers have increasingly emphasized the importance of making adaptations to treatment to meet the needs of the growing population of these high-risk groups in the United States (Bernal \& Rodriguez, 2009; Matos et al., 2006).

Parent-Child Interaction Therapy (PCIT) is one evidence-based program that has demonstrated positive outcomes with children with behavioral problems and shows promise for use with low-income and ethnic minority families (Eyberg et al., 2008; Fernandez et al., 2011). PCIT focuses on coaching the parent through interactions with their 
child in two parts. The first part works on strengthening the parentchild relationship through Child-Directed Interaction (CDI). Play, praise, and positive reinforcement are emphasized throughout this portion of therapy. As parents master the skills in CDI, they move on to Parent-Directed Interaction (PDI), where they learn to give effective requests and implement appropriate discipline strategies. PCIT is wellresearched within university lab settings, and has recently begun to be tested in applied settings with ethnically diverse populations (Fernandez et al., 2011). Matos et al. (2006) reported positive outcomes for an adapted version of PCIT with a sample of Puerto Rican families, where efforts were made to translate relevant treatment materials, seek feedback on the treatment process from parents and psychologists, and make necessary revisions to the treatment program after examining a pilot study with a group of nine families. Treatment revisions included an increased amount of time to work through possible interferences with treatment such as transportation, socioeconomic status, family and work stressors, translating necessary materials, and modifying reading material to fit parents' reading ability. The success of these adaptations was echoed in a study by McCabe and Yeh (2009) with a sample of 58 Mexican American families, suggesting that modifying evidence-based programs can be effective in producing positive treatment outcomes.

The Chicago Parent Program (CPP) has also demonstrated positive findings for use with low-income, diverse populations, including African American and Latino families using a group format (Gross et al., 2009). Through the use of minimal adaptations of childcentered time, rewards, and consequences for behaviors, parents were successful in reducing their child's challenging behaviors. Research suggests the generalizability of this model to at-risk ethnically diverse populations is contingent on making treatment adaptations an important component of manualized programs that require fidelity of implementation (Castro, Barrera, \& Martinez, 2004). Thus, finding a balance of fidelity and fit may be pivotal to participation, success, and maintenance of treatment gains for diverse, low-income populations.

In conclusion, ethnically diverse populations are disproportionately represented among those living in poverty (Gross et al., 2009) and their young children exhibit a higher incidence of 
behavior problems (Anthony et al., 2005; Fox \& Holtz, 2009; Gross et al., 2009). Moreover, contextual and cultural values play an important role in treatment outcomes (Barker, Cook, \& Borrego, 2010) and the efficacy of most currently available evidence-based programs were tested with primarily Caucasian middle-class families in clinic or university-based settings (Eyberg et al., 2008). Consequently, to move this field forward it is necessary to include ethnically diverse families in studies on the effectiveness of evidence-based treatments for early child behavior problems in naturalistic, community-based settings. Studies must also consider psychosocial barriers a priori that may affect attrition rates. In consideration of potential cultural differences between ethnic groups, the present study sought to gain information on treatment outcomes in low-income African American, Caucasian, and Latino families to examine the effectiveness of an in-home PCT program for behavior problems in young children.

\section{Method}

\section{Participants}

Participants included 183 families who were referred to an outpatient mental health clinic that specialized in providing homebased services for families of children 5 years of age and younger with significant behavioral or emotional problems (Fox, Keller, Grede, \& Bartosz, 2007). Referrals were made by parents or other caregivers (e.g., grandparents, foster parents); individual providers in private practice (e.g., pediatricians, public health nurses); and over 40 social service agencies, hospitals, schools, and daycare centers. Eligibility criteria for this study included: (a) the child was under 6 years of age; (b) the referral source expressed significant behavior or emotional concerns for the child such as aggression, destructiveness, hyperactivity, oppositional behavior, separation anxiety and/or selfinjury; (c) the child did not have significant physical disabilities, serious medical conditions, or present with symptoms suggesting the possibility of a Pervasive Developmental Disorder; (d) families were considered as program completers when they completed the treatment program including pretest, posttest, and a 4- to 6-week follow-up evaluation; and (e) the child's parent/guardian signed an IRBapproved consent form. Data were gathered until an equal number of 
participants were reached from each ethnic group who met the study's eligibility criteria and completed the treatment program.

Study data was collected over the course of 2 years. We defined minimal treatment participation as completion of an intake session and three treatment sessions. This definition was based on our frontloading the treatment program to deliver the major content within the first three treatment sessions. The remaining treatment sessions were devoted to assisting the families in implementing the treatment content covered during the first three treatment sessions until the treatment goals were achieved. An additional 83 families did not meet this minimal participation criterion. Of the 183 families that met the minimal participation criteria, 111 completed a posttest $(61 \%)$. Of the 111 that completed a posttest, 66 completed follow-up (60\%). The average wait time between posttest and follow-up assessment was 6.87 weeks $(S D=3.55)$. The most common reasons for early termination included caregivers not responding to repeated contacts following a missed session. Families were terminated from treatment following three unexcused cancellations. Some caregivers no longer desired services, had scheduling conflicts with jobs, or moved out of the area.

Of the 66 children that completed follow-up, 22 were African American $(M$ age $=2.88, S D=1.09), 22$ were Caucasian $(M$ age $=$ $2.90, S D=1.11$ ), and 22 identified as Latino or Hispanic ( $M$ age $=$ $2.81, S D=.922)$. More than half $(64 \%)$ of children met the criteria for at least one developmental delay, defined as scoring at least $25 \%$ below chronological age in one or more areas of development (e.g., speech, cognition, motor). The most common type of delay experienced by children in this sample was a speech delay (55.2\% of the total sample), followed by a motor delay $(12.1 \%)$, and cognitive delay $(8.6 \%)$. All developmental delays were previously diagnosed by independent evaluators from a Birth-to-Three agency. Within the Latino sample, 14 (64\%) families were primarily Spanish-speaking and required the use of an interpreter and translated treatment handouts. A Spanish-speaking paraprofessional was employed within the clinic to help facilitate treatment for primarily Spanish-speaking families. 
NOT THE PUBLISHED VERSION; this is the author's final, peer-reviewed manuscript. The published version may be accessed by following the link in the citation at the bottom of the page.

\section{Measures}

Early Childhood Behavior Screen (Ecbs). The Early Childhood Behavior Screen (ECBS; Holtz \& Fox, 2012) is a 20-item self-report instrument developed specifically for very young children (0- to 5years-old) from low-income backgrounds. The ECBS includes 10 positive behavior items (e.g., Listens to you, Shares toys) and 10 challenging behavior items (e.g., Hits others, has temper tantrums) and is written at a 3.9 grade level. The scale instructions ask caregivers to rate each item based on their perception of their child's behavior over the past week using a 3-point scale $(1=$ rarely/never, 2 = sometimes, $3=$ almost always/always). Total scores on the challenging behavior scale range from 10 to 30 with higher scores indicating a higher frequency of challenging behaviors. Total scores on the positive behavior scale range from 10 to 30 with higher scores indicating a higher frequency of prosocial behaviors. Original fieldtesting of the ECBS was conducted with a representative, diverse sample of 439 parents from a low-income urban community. Examination of reliability of the ECBS found the Challenging Behavior Scale (.87) and Positive Behavior Scale (.92) obtained good levels of internal consistency. The 10-item Challenging Behavior Scale demonstrated adequate levels of concurrent validity $(r=.75)$ with the Eyberg Child Behavior Inventory (ECBI; Eyberg \& Pincus, 1999). In addition, the ECBS Challenging Behavior Scale acquired adequate levels of sensitivity ( $82 \%)$, and specificity $(80 \%)$ based on its relationship with the ECBI.

Parent Behavior Checklist (Pbc). The PBC (Fox, 1994) is a 32-item rating scale that was designed to measure the behaviors and expectations of parents of young children between the ages of 1 year and 4 years, 11 months. The PBC consists of three scales that were empirically derived through factor analyses: Expectations-12 items that measure parents' developmental expectations (e.g., "My child should be quiet while I'm on the phone"); Discipline-10 items that assess parental responses to children's problem behaviors (e.g., "I yell at my child for whining"); and Nurturing-10 items that measure specific parent behaviors that promote a child's psychological growth (e.g., "My child and I play together on the floor"). Items are rated using a 4-point frequency scale $(4=$ almost always/always, $3=$ 
frequently, 2 = sometimes, and $1=$ almost never/never). The range of total scores for each subscale are: Expectations (range $=12-48$ ) with higher scores indicating higher parental expectations, Discipline (range $=10-40$ ) with higher scores indicating more frequent use of verbal and corporal punishment (e.g., yelling, spanking), and Nurturing (range $=10-40$ ) with higher scores suggesting more frequent use of positive nurturing activities. From a representative sample of 1,140 mothers, the following internal consistencies using coefficient alphas were reported: Expectations $=.97$, Discipline $=.91$, and Nurturing $=.82$. Test-retest reliabilities for each of the three subscales were: Expectations $=.98$, Discipline $=.87$, and Nurturing $=.81$.

Direct Observation of Parent-Child Interactions. Parents were instructed to play with their child with a standard set of toys while the clinician observed and rated the quality of the parent and child interaction. Based on the work of Crawley and Spiker (1983), five dimensions of the child's behavior (positive affect, negative affect, interest in play, initiation, social responsiveness) and five dimensions of the parent's behavior (parent leading play, child leading play, parent sensitivity, parent expectations, parent limit setting) were rated using a 5 -point scale $(1=$ never, $2=$ seldom, $3=$ average, $4=$ usually, $5=$ always). Separate total scores were computed for the five dimensions of the child's behaviors and the five dimensions of the parent's behaviors. Coefficient alphas were reported for the total child scores (.85) and the total parent scores (.83; Fox, et al., 2007). Coefficient alphas for the present sample were computed for the child behavior score $(r=.76)$ and the parent behavior score $(r=.79)$.

Family Satisfaction Survey. A 7-item survey was used to assess caregiver satisfaction with the treatment services. Using a 7point scale, caregivers were asked to rate the quality of services received $(1=$ poor to $7=$ excellent $)$, how the services contributed to their child's improvement $(1=$ not at all to $7=a$ lot $)$, how the clinic helped them improve how they managed their child's behaviors $(1=$ not at all to $7=a$ lot), if caregivers would use the clinic again if needed $(1=$ no, definitely not to $7=y e s$, definitely), the current status of child's referral concern $(1=$ considerably worse to $7=$ greatly improved), if caregivers would recommend the clinic to others $(1=$ no, definitely not to $7=y e s$, definitely $)$, and the caregiver's 
confidence in managing their children's behavior in the future ( $1=$ not at all confident to $7=$ very confident). For the present sample, the internal consistency for these seven items was $r=.77$.

\section{Procedures}

Referral and Intake. A referral form including the referral source, family contact information, and the child's age and referral concerns was required to initiate Parent-Child Therapy (PCT) services. Upon receipt of the completed referral form, parents were contacted to obtain more information about their concerns, to determine the eligibility of the child for the study, to describe the clinic's treatment program, and to explain the important role of the primary caregiver in treatment. Eligible children were placed on a waiting list to be scheduled for an intake when a clinician became available. Parents of ineligible children were provided referrals to other agencies. An initial, 2-hour intake evaluation session was conducted that included a review of available records and a comprehensive parent interview to determine the history and current environmental factors that contributed to the child's referral concern. In addition, parents were asked to play with their child as they normally do while observations of the parent and child interaction were rated and the study's self-report measures were completed. The first treatment session was scheduled within one week of the intake date.

Parent and Child Therapy Program. An evidence-based treatment program designed specifically for parents of young children (Fox \& Nicholson, 2003) was adapted for individual use in the home and included five components: (a) nondirective play and the encouragement of increased nurturing activities in the home and community to strengthen the parent-child relationship; (b) teaching parents to thoughtfully interact instead of emotionally overreact in a negative manner to their child's problem behaviors; (c) teaching parents to establish appropriate developmental expectations for their children; $(d)$ increasing the child's prosocial behaviors through positive reinforcement, establishing home routines, and giving clear, developmentally appropriate instructions; and (e) reducing the child's problem behaviors through the use of redirection, active ignoring, natural consequences, and time-out. Treatment sessions typically 
lasted from 60 to 90 minutes. In the PCT program, treatment strategies were explained to the parent and directly modeled by the clinician. Parents also practiced each strategy with their children during the treatment sessions and received immediate feedback from the clinician. Handouts were provided to explain treatment strategies in more detail as were all other materials needed to implement the treatment (e.g., edible and tangible reinforcers, toys, door gates for time-out, safety latches for kitchen cupboards). The treatment program was designed to be completed in eight, once-weekly treatment sessions; however, sometimes more sessions were needed to meet the treatment goals. For the present study, families who completed the PCT program participated in an average of 8.83 weekly sessions ( $S D=3.21$ ) over the course of approximately 10 weeks $(M=$ $10.37, S D=4.41)$. There were no differences between groups on time to completion or number of sessions attended $(p>.05)$. In addition to the treatment sessions, all participants participated in separate pretest (intake), posttest, and 4- to 6-week follow-up evaluations. Minor adaptations were made to the treatment program for Spanishspeaking families which included translated treatment materials and the use of an interpreter to moderate treatment sessions. Other minor adaptations included the clinicians matching communication style of a family and using concrete examples and direct modeling to illustrate treatment strategies to ensure comprehension of treatment materials.

Clinician Training. Clinicians were master's level, licensed therapists and graduate students in counseling and psychology programs who received practicum and internship course credit for their participation in this study. All clinicians received extensive training and supervision in four modules: (a) working with diverse families of young children with and without developmental delays who live in poverty and maintaining personal safety in the home setting; (b) clinical skills needed for interacting with children less than 6 years of age and their caregivers; (c) treatment theory, program content, and procedures; and (d) assessment administration and data collection. Training included didactic instruction based on a comprehensive training manual, reviewing relevant empirical literature articles, watching treatment program videotapes and rating parent-child interactions to ensure interrater reliability, shadowing treatment sessions, and a gradual assumption of the role of lead clinician in the field under close permission has been granted for this version to appear in e-Publications@Marquette. Taylor \& Francis (Routledge) does not grant permission for this article to be further copied/distributed or hosted elsewhere without the express permission from Taylor \& Francis (Routledge). 
supervision. Each clinician participated in ongoing weekly supervision (group and individual) for assistance on specific issues that arose with families and for feedback on their performance while implementing the treatment program. In general, clinicians completed training within approximately 4-5 months, at which time they began carrying a caseload of five to seven families. As most of the children's homes were located in unsafe neighborhoods, clinicians often provided treatment services in pairs and had access to an on-call supervisor if needed.

\section{Results}

Demographic data for the children and their caregivers are shown in Table 1. A series of ANOVAs for the continuous variables and chi-square tests for the discrete variables revealed no significant differences between groups on child's age, gender, primary caregiver, whether the family received public assistance, or presence of developmental delay.

The goal of the subsequent analyses was to examine how parents and children change over time from pretest to posttest and follow-up and if these changes were related to group membership. The results for these analyses were divided into two parts and are presented as follows: child variables (ECBS challenging scale, Child observation ratings), and parent variables (PBC nurturing and discipline subscales, Parent observation ratings, PBC expectations subscale). We selected $p=.05$ as our significance level. We decided against a more conservative approach (e.g., Bonferroni correction), given the exploratory nature of this study in a nontraditional setting. Also, in addition to traditional statistical comparisons we focused on effect sizes throughout the Results section to demonstrate the clinical significance of the study.

\section{Child Variables}

ECBS Challenging Scale. To examine the change in the frequency of the children's challenging behaviors over time, a repeated measures ANOVA was computed. Assumptions were met and post hoc analyses were planned for the main effect of time as well as ethnicity 
by time interaction. There was a significant main effect for time, $F(2$, $126)=49.59, p<.01$, partial $\eta^{2}=.44$, with no interaction effect $(p$ $=.61)$. The within-subjects contrasts indicated a significant decrease in scores occurred from pretest to posttest assessment, $F(1,63)=$ 96.39, $p<.01$, partial $\eta^{2}=.61$. The between-subjects ANOVAs did not reveal significant differences in the frequency of children's challenging behaviors across ethnic groups. Effect sizes indicated that African American, Caucasian, and Latino groups all experienced a moderate drop in ECBS challenging scale scores from pretest to posttest. These changes were maintained from posttest to follow-up across groups without significant differences from the posttest to follow-up.

Child Observation Ratings. To examine change in the quality of the child's interactions with their parent during the play assessment, a repeated measures ANOVA was performed on the sum of the five items from the child portion of the parent and child observation scale at pretest, posttest, and follow-up. Results indicated a significant main effect for time, $F(1.935,106.40)=20.68, p<.01$, partial $\eta^{2}=.27$, with no interaction effect $(p=.12)$. The within-subjects contrasts revealed these effects occurred from pretest to posttest, $F(1,55)=$ 23.98, $p<.001$, partial $\eta^{2}=.30$. African American, Caucasian, and Latino children's play interaction changed across administrations. The between-subjects ANOVA also revealed significant differences for ethnicity, $F(2,55)=4.50, p=.02$, partial $\eta^{2}=.14$. Latino children had significantly higher child play ratings at posttest compared to Caucasian children, but not African American children. The positive effects of children's interactions during play were maintained from posttest to follow-up, with the Latino and Caucasian groups showing a trend toward an increase after treatment.

\section{Parent Variables}

PBC Nurturing and Discipline Scales. To examine how parents' nurturing and discipline changed over time, a repeated measures MANOVA was performed on the two measures of parent behaviors (nurturing and discipline) over three test administrations (pretest, posttest, and follow-up). The main effect for ethnicity was not significant (partial $\eta^{2}=.05$ ), however; the main effect for time was significant (partial $\eta^{2}=.20$ ). The within-subjects contrasts for the 
main effect of time revealed significant change for discipline from pretest to posttest, $F(2,63)=4.52, p=.02$, partial $\eta^{2}=.13$ (see Table 2). To test the assumptions for a MANOVA, Mauchly's test was conducted and indicated that the assumption of sphericity had been violated for nurturing, $\mathrm{x}^{2}(2)=18.00, p<.01, \epsilon=.80$; and discipline $X^{2}(2)=15.56, p<.01, \epsilon=.82$; therefore, degrees of freedom were corrected using Greenhouse-Geisser estimates of sphericity. With this correction, there was a significant effect for the time by ethnicity interaction for discipline, $F(3.273,103.112)=2.67, p=.05$, partial $\eta^{2}$ $=.08$; but not nurturing, $F(3.19,100.64)=.69, p=.57$, partial $\eta^{2}$ $=.02$. The African American and Caucasian groups decreased approximately 10 points on the discipline scale from pretest to posttest, placing them in the average to low-average range for use of harsh discipline at posttest, while the Latino group showed a smaller decrease from pretest to posttest and continued to decrease at followup. The Latino group showed a smaller decrease in scores from pretest to posttest, but reported lower levels of discipline at pretest than both of the other groups.

Parent Observation Ratings. To examine change in the quality of the parent's interactions with their child during the play assessment, a repeated measures ANOVA was performed on the sum of five parent variables on the parent portion of the parent and child observation scale. There was a significant main effect for time, $F(2,54)=35.84, p$ $<.01$, partial $\eta^{2}=.57$. African American, Caucasian, and Latino parents improved significantly on the quality of their play interaction from pretest to posttest (Table 2). The ethnicity by time interaction was also significant, $F(4,110)=2.43, p=.05$, partial $\eta^{2}=.08$. Parent interaction ratings differed across ethnic groups. Specifically, African American parents were rated lower while interacting with their child during pretest than the Latino or Caucasian groups, but showed comparably large gains in their ability to interact appropriately during play with their child from pretest to posttest. African American and Latino families showed the highest reported scores on the parent-child interaction measure at posttest. No significant change occurred between posttest and follow-up for any group.

Parental Expectations (PBC). To accommodate for different expected outcomes on the parental expectations subscale, the total 
sample $(N=66)$ was divided into three subgroups that identified them as having either low ( $t$ scores of $<35$ ), average ( $t$ scores between 3565 ), or high ( $t$ scores $>.65$ ) parental expectations. Groups were not divided by ethnicity due to the sample size being too small to conduct the analysis after being split by both expectations level and ethnic group. Repeated measures ANOVAs were done to examine changes on scores at each of the three expectations levels, followed by paired samples $t$ tests to determine the source of change with group assignment (low, average, high) as the independent variable and time as the dependent variable (see Table 2). Results indicated a significant main effect for time for each group from pretest to posttest. Parents who reported having low expectations at pretest ( $t$ scores $<35$ ) increased their expectations to an age-appropriate level at posttest $t(11)=-2.20, p=.05, d=-0.98$. Parents who reported developmentally appropriate expectations for their child at pretest showed a decrease in their expectations at posttest while still remaining in the normal range, $t(43)=2.94, p=.01, d=0.39$. Parents who had high expectations ( $t$ scores $>.65$ ) at pretest showed a decrease to the average range on expectations at posttest, $t(9)=$ $3.31, p=.01, d=1.34$, and maintained this level of expectations at follow-up.

\section{Satisfaction Survey}

Sixty parents (91\%) completed the parent satisfaction questionnaire. Parents rated the quality of the program highly $(M=$ $6.73, S D=0.66)$, indicating that they viewed the services as good to excellent. No differences between groups on this measure were found. Parents reported that the program helped improve their child's behavior $(M=5.97, S D=1.28)$ and increased their confidence in their ability to manage their child's behavior in the future $(M=5.85, S D=$ 1.09). Parents also indicated that they would recommend the ParentChild Therapy (PCT) program to others to address their child's behavior problems.

\section{Discussion}

The purpose of this study was to examine treatment outcomes for a home-based PCT program in low-income African American, 
Caucasian, and Latino families with young children who display significant behavior problems. Results of this study demonstrated acceptability for the use of such a PCT program with diverse populations living in poverty. At posttest, parents of all groups reported a decreased frequency of their child's challenging behaviors, increased positive interactions with their child during play, improved parental expectations, higher levels of nurturing, and less reliance on the use of verbal and corporal punishment. At a 4- to 6-week follow-up session, these treatment gains had not changed significantly from posttest outcomes. The effect sizes for these pretreatment to posttreatment changes were in the moderate range. Clinically, changes in the ECBS scores overall along with parent comments indicated that many parents felt the frequency of their child's challenging behavior had decreased dramatically from pretest to posttest. Reports of family satisfaction with services are consistent with the drop in ECBS scores reflecting that families felt their child's behavior improved significantly as a result of the program and that they would recommend services to others with similar needs.

One measure that produced significant effects of ethnicity by time was the clinician ratings of parent interactions with their child during play. On that measure, African American parents showed larger gains from beginning to the end of treatment in the quality of their interactions with their child during play compared to Caucasian and Latino parents. This could be due to a number of factors. First, it could be that within our study, African American parents' parenting style was more authoritarian in nature, which would imply the primary caregiver takes on the role of disciplinarian instead of nurturer in the family. It could also be that African American parents responded well to our treatment modality that emphasizes the importance of creating a positive foundation of play before moving on to other more difficult strategies. In our study, Latino parents demonstrated the highest aggregate score of clinician-rated play interactions with their child at pretest and posttest, which is consistent with cultural value of familismo, or the importance of family in Latino culture; and personalismo, the Latino emphasis on warm and trusting interpersonal relationships. These cultural values suggest that caregivers (typically mothers) would be likely to provide high levels of nurturing to their children (Barker et al., 2010). Another reason the Latino group may

Child \& Family Behavior Therapy, Vol. 36, No. 1 (2014): pg. 33-50. DOI. This article is (c) Taylor \& Francis (Routledge) and permission has been granted for this version to appear in e-Publications@Marquette. Taylor \& Francis (Routledge) does not grant permission for this article to be further copied/distributed or hosted elsewhere without the express permission from Taylor \& Francis (Routledge). 
have demonstrated different results from the African American and Caucasian groups is that they potentially could have had a qualitatively different experience through treatment as a result of the steps taken to adapt treatment to fit their needs (e.g., interpreter, translated materials, discussion of cultural values). This experience could have led to differences in the development of the therapeutic relationship, emotional investment, and empathy relative to the other groups during treatment and should not be overlooked as a potential confounding variable.

The other measure that revealed an interaction between time and ethnicity was the discipline subscale on the PBC. While the African American and Caucasian groups showed similar trends in decreasing scores from pretest to posttest with maintenance of scores from posttest to follow-up, the Latino group exhibited both lower levels of parent-reported use of harsh discipline at pretest and significantly lower levels of discipline from posttest to follow-up. This trend could be attributed to Latino parents relying less on harsh discipline (i.e., yelling, spanking) from the outset, but not knowing what to do or how to consistently implement developmentally appropriate strategies when their child did demonstrate challenging behaviors. Thus, further decreased use of harsh discipline at 4- to 6-week follow-up may have been a result for the program helping parents learn how to implement effective alternative discipline methods (e.g., time-out) consistently in their home.

The results of this study are consistent with previous research demonstrating the efficacy of parenting programs for managing young children's challenging behaviors and add to the limited research addressing sociocultural variables in working with low-income African American, Caucasian, and Latino families (Fernandez et al., 2011; Fox \& Holtz, 2009). With the inclusion of minimal adaptations for the Latino group (i.e., translated treatment materials from English to Spanish, having a Spanish-speaking paraprofessional interpret treatment to family), the PCT program demonstrated success across groups. Another reason our program may have been successful is because the program meets families where they are at in their homes. Not only does this allow us to compensate for potential barriers to treatment (e.g., transportation, inability to find day care for other 
children), it also opens a window into a family's natural environment. Working within this scope, we are better equipped to work on an individual basis for families requiring adaptation (e.g., slowing down treatment sessions, taking extra time in teaching difficult strategies, addressing issues as they arise in the home). These adaptations would be difficult in the more frequently used group format for parent training.

The results of this study should be interpreted with caution. First, this study did not employ a treatment control group. Without a control group it is impossible to determine the true effectiveness of this program across ethnic groups. While the effectiveness of the treatment strategies used in this program have been well-established in the literature (Fox \& Holtz, 2009), inherent challenges to providing services to this population prevented us from recruiting a control group for this study. Another limitation of this study is the limited availability of interrater reliability for clinician observation measures. Because the support clinician is typically a student in training, it can be difficult to have two individuals attending an intake evaluation who are well-trained with the coding procedures for this measure. Future studies should focus on training students on the coding rules for the parent and child observation tool up front to ensure availability of interrater data. The majority of the dependent variables in this study was parent report, and as such could be interpreted as subjective; future studies should incorporate the use of multi-method, multiinformant strategies to avoid reporting biases.

Another weakness of the study is the lack of information provided regarding the type of developmental delay or level of impairment of delay in the current sample. Previous research examining the presence of developmental delays in this same population has found no differences in treatment outcomes between groups (Holtz, Carrasco, Mattek, \& Fox, 2009). However, incorporating the level of impairment of delays into future studies could be valuable to improve the validity of results within the population. Further, it would be interesting to examine whether cumulative effects of the presence of multiple delays exist and how they might impact treatment outcomes in this program. 
Notwithstanding these limitations, the results of this study have important practical implications for the use of an in-home PCT program for low-income African American, Caucasian, and Latino families. This PCT program demonstrates positive results with minimal adjustments to the treatment protocol to fit the cultural and contextual needs of low-income and ethnically diverse families receiving home-based mental health services. The results from this study show that African American, Caucasian, and Latino parents can make positive change in their parenting behaviors and subsequently see a decrease in their child's challenging behaviors after a relatively short period of time, averaging roughly eight once-weekly treatment sessions. Given negative implications for the trajectory of young children's untreated challenging behaviors, effective short-term early intervention programming that meets engaged families' unique treatment needs is the key to helping parents make long-term positive change in their child's behaviors.

\section{Funding}

This research was supported in part by grants from the Argosy Foundation, Brighter Futures of Milwaukee, Charles D. Jacobus Family Foundation, Exchange Clubs of Greater Milwaukee Charitable Foundation, Faye McBeath Foundation, Helen Bader Foundation, Schauss Family, Stackner Family Foundation, and United Way.

\section{Acknowledgments}

The authors acknowledge the support of Penfield Children's Center, the Birthto-Three Agency that served as the site for this study, and the family clinicians and graduate students who provided mental health services for the children and their families.

\section{Notes}

Note. ${ }^{a} n=22 .{ }^{b} n=22 .{ }^{c} n=22$. Public assistance $=$ family reported receiving government aid in form of insurance, food stamps, or other support. In order to receive government aid, total family income must fall below the federal poverty level.

Note. ECBS $=$ Early Childhood Behavior Screen; PBC $=$ Parent Behavior Checklist. 
NOT THE PUBLISHED VERSION; this is the author's final, peer-reviewed manuscript. The published version may be accessed by following the link in the citation at the bottom of the page.

\section{References}

American Psychological Association. (2000). Diagnostic and statistical manual of mental disorders (4th ed. text revision). Washington, D.C.: Author.

Anthony, B. J., Anthony, L. G., Morrel, T. M., \& Acosta, M. (2005). Evidence for social and behavior problems in low-income, urban preschoolers: Effects of site, classroom, and teacher. Journal of Youth and Adolescence, 34, 31-39.

Barker, C. H., Cook, K. L., \& Borrego, J. Jr. (2010). Addressing cultural variables in parent training programs with Latino families. Cognitive and Behavioral Practice, 17, 157-166.

Bernal, G., \& Rodriguez, M. D. (2009). Advances in Latino family research: Cultural adaptations of evidence-based interventions. Family Process, 48(2), 169-178.

Breitenstein, S. M., Gross, D., Ordaz, I., Julion, W., Garvey, C., \& Ridge, A. (2007). Promoting mental health in early childhood programs serving families from low-income neighborhoods. Journal of the American Psychiatric Nurses Association, 13, 313-320.

Campbell, S. B. (1995). Behavior problems in preschool children: A review of recent research. Journal of Child Psychology \& Psychiatry, 36, 113149.

Castro, F. G., Barrera, M. Jr., \& Martinez, C.R. Jr. (2004). The cultural adaptation of prevention interventions: Resolving tensions between fidelity and fit. Prevention Science, 5(1), 41-45.

Coard, S. I., Wallace, S. A., Stevenson, H. C. Jr., \& Brotman, L. M. (2004). Towards culturally relevant preventive interventions: The consideration of racial socialization in parent training with African American families. Journal of Child and Family Studies, 13(3), 277-293.

Crawley, S. B., \& Spiker, D. (1983). Mother-child interactions involving twoyear-olds with Down syndrome: A look at individual differences. Child Development, 54, 1312-1323.

Eyberg, S. M., Boggs, S., \& Algina, J. (1995). Parent-child interaction therapy: A psychosocial model for the treatment of children with conduct problem behavior and their parents. Psychopharmacology Bulletin, 31, 83-91.

Eyberg, S.M., Nelson, M.N., \& Boggs, S.R. (2008). Evidence-based psychological treatments for children and adolescents with disruptive behavior. Journal of Clinical Child and Adolescent Psychology, 37(1), 215-237.

Eyberg, S. M., \& Pincus, D. (1999). Eyberg Child Behavior Inventory and the Sutter-Eyberg Student Behavior Inventory-Revised. Lutz, FL: Psychological Assessment Resources, Inc.

Child \& Family Behavior Therapy, Vol. 36, No. 1 (2014): pg. 33-50. DOI. This article is (C) Taylor \& Francis (Routledge) and permission has been granted for this version to appear in e-Publications@ Marquette. Taylor \& Francis (Routledge) does not grant permission for this article to be further copied/distributed or hosted elsewhere without the express permission from Taylor \& Francis (Routledge). 
Fernandez, M. A., Butler, A. M., \& Eyberg, S. M. (2011). Treatment outcome for low socioeconomic status African American families in parent-child interaction therapy: A pilot study. Child \& Family Behavior Therapy, 33, 32-48. doi: 10.1080/07317107.2011.545011

Fox, R. A. (1994). Parent behavior checklist. Austin, TX: ProEd (Currently available from the author, Marquette University, School of Education, P.O. Box 1881, Milwaukee, WI 53201-1881; Email:robert.fox@marquette.edu).

Fox, R. A., \& Holtz, C. A. (2009). Treatment outcomes for toddlers with behavior problems and developmental delays from low-income families. Child and Adolescent Mental Health, 14(4), 183-189. doi: 10.1111/j. 1475-3588.2009.00527.x

Fox, R. A., Keller, K. M., Grede, P. L., \& Bartosz, A. M. (2007). A mental health clinic for toddlers with developmental delays and behavior problems. Research in Developmental Disabilities, 28, 119-129.

Fox, R. A., \& Nicholson, B. C. (2003). Parenting young children: A facilitator's guide. Longmont, Colorado: Sopris West.

Gross, D., Garvey, C., Julion, W., Fogg, L., Tucker, S., Mokros, H. (2009). Efficacy of the Chicago Parent program with low-income African American and Latino parents of young children. Prevention Science, 10, 54-65. doi: 10.1007/s11121-008-0116-7

Holtz, C. A., Carrasco, J. M., Mattek, R. J., \& Fox, R. A. (2009). Behavior problems in toddlers with and without developmental delays: Comparison of treatment outcomes. Child \& Family Behavior Therapy, 31, 292-311.

Kataoka, S. H., Zhang, L., \& Wells, B. (2002). Unmet need for mental health care among U.S. children: Variation by ethnicity and insurance status. American Journal of Psychiatry, 159, 1548-1555.

Kazdin, A. E., Mazurick, J. L., \& Bass, D. (1993). Risk for attrition in treatment of antisocial children and families. Journal of Clinical Child Psychology, 22(1), 2-16.

Keenan, K., \& Wakschlag, L. (2000). More than the terrible twos: The nature and severity of behavior problems in clinic-referred preschool children. Journal of Abnormal Child Psychology, 28, 33-46.

Keenan, K. Shaw, D., Delliquadri, E., Giovannelli, J., \& Walsh, B. (1998). Evidence for the continuity of early problem behaviors: Application of a developmental model. Journal of Abnormal Child Psychology, 26(6), 441-454.

Matos, M., Torres, R., Santiago, R., Jurado, M., \& Rodriguez, I. (2006). Adaption of parent-child interaction therapy for Puerto Rican families: A preliminary study. Family Process, 45(2), 205-222.

McCabe, K., \& Yeh, M. (2009). Parent-child interaction therapy for Mexican Americans: A randomized clinical trial. Journal of Clinical Child \&

Child \& Family Behavior Therapy, Vol. 36, No. 1 (2014): pg. 33-50. DOI. This article is (c) Taylor \& Francis (Routledge) and permission has been granted for this version to appear in e-Publications@Marquette. Taylor \& Francis (Routledge) does not grant permission for this article to be further copied/distributed or hosted elsewhere without the express permission from Taylor \& Francis (Routledge). 
NOT THE PUBLISHED VERSION; this is the author's final, peer-reviewed manuscript. The published version may be accessed by following the link in the citation at the bottom of the page.

Adolescent Psychology, 38(5), 753-759. doi:

$10.1080 / 15374410903103544$

Nicholson, B. C., Brenner, V., \& Fox, R. A. (1999). A community-based parenting program with low-income mothers of young children. Families in Society: The Journal of Contemporary Human Services, 80, 247-253.

Reid, M. J., Webster-Stratton, C., \& Beauchaine, T. P. (2002). Parent training in head start: A comparison of program response among African American, Asian American, Caucasian, and Hispanic mothers. Prevention Science, 2(4), 209-227.

Substance Abuse and Mental Health Services Administration. (2001). Mental health; culture, race, and ethnicity - A supplement to mental health: A report of the Surgeon General. Rockville, MD: U.S. Department of Health and Human Services.

Sanders, M.R., Markie-Dadds, C., Tully, L.A., \& Bor, W. (2000). The Triple PPositive parenting program: A comparison of enhanced, standard, and self-directed behavioral family intervention for parents of children with early onset conduct problems. Journal of Consulting and Clinical Psychology, 68, 634-640.

Viera, A. J., \& Garrett, J. M. (2005). Understanding interobserver agreement: The Kappa statistic. Family Medicine, 37(5), 360-363.

Webster-Stratton, C., \& Hammond, M. (1997). Treating children with earlyonset conduct problems: A comparison of child and parent training interventions. Journal of Consulting and Clinical Psychology, 65, 93109.

Webster-Stratton, C., Ried, M., \& Hammond, M. (2001). Preventing conduct problems, promoting social competence in Head Start children: Prevalence, pervasiveness, and associated risk factors. Clinical Child and Family Psychology Review, 1, 101-124.

Child \& Family Behavior Therapy, Vol. 36, No. 1 (2014): pg. 33-50. DOI. This article is (c) Taylor \& Francis (Routledge) and permission has been granted for this version to appear in e-Publications@Marquette. Taylor \& Francis (Routledge) does not grant permission for this article to be further copied/distributed or hosted elsewhere without the express permission from Taylor \& Francis (Routledge). 
NOT THE PUBLISHED VERSION; this is the author's final, peer-reviewed manuscript. The published version may be accessed by following the link in the citation at the bottom of the page.

Table 1. Demographic Data for Caucasian, African American, and Latino Groups At Pre-Treatment

\begin{tabular}{|c|c|c|c|c|c|c|c|c|c|c|c|c|}
\hline \multirow[b]{2}{*}{ Variable } & \multicolumn{4}{|c|}{ African American" } & \multicolumn{4}{|c|}{ Caucasian } & \multicolumn{4}{|c|}{ Latino $^{5}$} \\
\hline & $M$ & $S D$ & $n$ & $\%$ & $M$ & $S D$ & $n$ & $\%$ & $M$ & $S D$ & $n$ & $\%$ \\
\hline Age of Child & 2.88 & 1.11 & 22 & & 2.90 & 1.09 & 22 & & 2.81 & 922 & 22 & \\
\hline \multicolumn{13}{|l|}{ Gender } \\
\hline Male & & & 15 & $68.2 \%$ & & & 18 & $81.8 \%$ & & & 17 & $77.3 \%$ \\
\hline Female & & & 7 & $31.8 \%$ & & & 4 & $18.2 \%$ & & & 5 & $22.7 \%$ \\
\hline \multicolumn{13}{|c|}{ Primary Caretaker } \\
\hline Mother & & & 17 & $77.3 \%$ & & & 20 & $90.9 \%$ & & & 20 & $90.9 \%$ \\
\hline Father & & & 1 & $4.50 \%$ & & & 2 & $9.10 \%$ & & & 1 & $4,50 \%$ \\
\hline Grandmother & & & 2 & $9.10 \%$ & & & 0 & $0.00 \%$ & & & 1 & $4.50 \%$ \\
\hline Other & & & 2 & $9.10 \%$ & & & 0 & $0.00 \%$ & & & 0 & $0.00 \%$ \\
\hline \multicolumn{13}{|c|}{ Public Assistance } \\
\hline Yes & & & 19 & $86.4 \%$ & & & 18 & $81.8 \%$ & & & 22 & $100 \%$ \\
\hline No & & & 3 & $13.6 \%$ & & & 4 & $18.2 \%$ & & & 0 & $0.00 \%$ \\
\hline \multicolumn{13}{|c|}{$\begin{array}{l}\text { Presence of } \\
\text { Developmental Delay }\end{array}$} \\
\hline Yes & & & 11 & $50.0 \%$ & & & 12 & $54.5 \%$ & & & 14 & $63.6 \%$ \\
\hline No & & & 11 & $50.0 \%$ & & & 10 & $45.5 \%$ & & & 8 & $36.3 \%$ \\
\hline
\end{tabular}

Note: $\mathrm{a} n=22 . \mathrm{b} n=22 . \mathrm{c} n=22$. Public Assistance $=$ family reported receiving government aid in form of insurance, food stamps, or other support. In order to receive government aid, total family income must fall below the federal poverty level.

Table 2. Means and Standard Deviations for African American, Caucasian, and Latino groups at Pre-, Post-, and Follow-up

\begin{tabular}{|c|c|c|c|c|c|c|c|c|c|c|c|c|c|c|c|c|c|c|}
\hline \multirow[b]{3}{*}{6} & \multicolumn{6}{|c|}{ 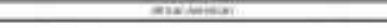 } & \multicolumn{6}{|c|}{ Zut } & \multicolumn{6}{|c|}{$\underline{t=}$} \\
\hline & \multicolumn{2}{|c|}{ mase } & \multicolumn{2}{|c|}{ saren } & \multicolumn{2}{|c|}{ nese } & \multicolumn{2}{|c|}{ 드름 } & \multicolumn{2}{|c|}{ man } & \multicolumn{2}{|c|}{1004} & \multicolumn{2}{|c|}{ nexe } & \multicolumn{2}{|c|}{ Easas } & \multicolumn{2}{|c|}{$\operatorname{cosen} x$} \\
\hline & $=$ & 30 & 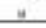 & as & $\approx$ & if & 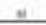 & 10 & $n$ & it & $=$ & in & 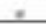 & in & $\mu$ & $m$ & $\mu$ & 30 \\
\hline his & & & & & & & & & & & & & & & & & & \\
\hline ad were & करण & 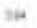 & ine & is & tios & 4 & 20 & ws & $w=$ & ant & tis & 44 & zis & . & 10 & 40 & 11.2 & $=$ \\
\hline 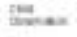 & wa & aw & $=0$ & 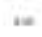 & $=\mathrm{at}$ & in & was & in & wai & an & inat & $2 w$ & wat & $1=$ & twa & iw & $w=$ & $=n$ \\
\hline porenen & & & & & & & & & & & & & & & & & & \\
\hline 100 & $a x$ & a & $=0$ & 120 & ain & $y \leq$ & ant & $\theta=$ & $a=$ & $n=$ & $\omega=$ & the & 300 & ast & wow & $i m$ & $\operatorname{tax}$ & mas \\
\hline$=0$ & $\sin \frac{\pi}{2}$ & $\neq w$ & aws & $4 \pi$ & $=n$ & wat & Nen & 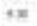 & $* n$ & mi & $m=n$ & sai & $n=$ & ail & nis & $\omega$ & $w a=$ & an \\
\hline 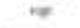 & niw & in & $w=$ & $=$ & abo & an & a a & 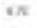 & $\omega=$ & $=$ & $s=$ & in & nis & $\infty$ & 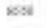 & tia & ars & 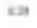 \\
\hline inns & $\omega w$ & is & $=6$ & w & $=\infty$ & ais & $f \times$ & $m \mathrm{~s}$ & $\omega=$ & ens & Whe & ist & est & 30 & था & in & ant & $=n$ \\
\hline nemp & $=\mathrm{n}$ & wn & $n=$ & n= & $w=$ & an & nis. & os & $w$ & $\mathrm{~F} *$ & $w n$ & $*$ & $=$ & $n$ & $\approx$ & $=a$ & $\mathrm{ma}$ & in \\
\hline$B=$ & $18 \%$ & 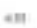 & $=0$ & is & 1ayt. & $4=$ & $m n$ & 10 & $n n$ & 39 & 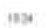 & as & $w s$ & 14 & $m$ & in & $m \mathrm{k}$ & $3 \pi$ \\
\hline
\end{tabular}

Child \& Family Behavior Therapy, Vol. 36, No. 1 (2014): pg. 33-50. DOI. This article is (C) Taylor \& Francis (Routledge) and permission has been granted for this version to appear in e-Publications@Marquette. Taylor \& Francis (Routledge) does not grant permission for this article to be further copied/distributed or hosted elsewhere without the express permission from Taylor \& Francis (Routledge) 